Slavica

bruxellensia

\section{Slavica bruxellensia}

Revue polyphonique de littérature, culture et histoire

slaves

$6 \mid 2010$

Linguistique russe

\title{
Andrzej Stasiuk, Mon Allemagne
}

\section{Maciek Vanhonnaeker}

\section{OpenEdition \\ Journals}

\section{Édition électronique}

URL : http://journals.openedition.org/slavica/366

DOI : 10.4000/slavica.366

ISSN : 2034-6395

\section{Éditeur}

Université libre de Bruxelles - ULB

\section{Édition imprimée}

Pagination : 70-71

ISSN : 2031-7654

\section{Référence électronique}

Maciek Vanhonnaeker, «Andrzej Stasiuk, Mon Allemagne », Slavica bruxellensia [En ligne], 6 | 2010, mis en ligne le 15 juin 2010, consulté le 22 septembre 2020. URL : http://journals.openedition.org/slavica/ 366 ; DOI : https://doi.org/10.4000/slavica.366

Ce document a été généré automatiquement le 22 septembre 2020.

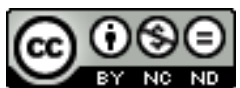

Les contenus de Slavica bruxellensia sont mis à disposition selon les termes de la Licence Creative Commons Attribution - Pas d'Utilisation Commerciale - Pas de Modification 3.0 France. 


\section{Andrzej Stasiuk, Mon Allemagne}

Maciek Vanhonnaeker

\section{RÉFÉRENCE}

Andrzej Stasiuk, Mon Allemagne, Paris, Christian Bourgois, 2010, 93 p. Traduit du polonais par Charles Zaremba 
"Arrête-toi maintenant, et je te ferai entendre la parole de Dieu» (p.7). Ces paroles du prophète Samuel font partie des premiers mots d'un livre tissé d'arrêts dans la course des instants et du flux de la pensée. Mon Allemagne, que l'on lit d'une traite, comme porté par le verbe admirablement traduit, met en scène la solitude d'Andrzej Stasiuk pris dans les rets de ses tournées littéraires à travers l'Allemagne, entre les hôtels, les transports et les «Literaturhausen ». Mû entre les interstices de l'ennui par le lieu immobile et mouvant de sa mémoire, labyrinthe de souvenirs flous ou précis à la temporalité indistincte, d'aéroports en aéroports, de gares en gares, où les horloges, mêmes tues, sont présentes dans l'étirement de la durée. L'auteur lui-même ne cherche pas ses souvenirs, il contemple le paysage de sa mémoire, s'efface

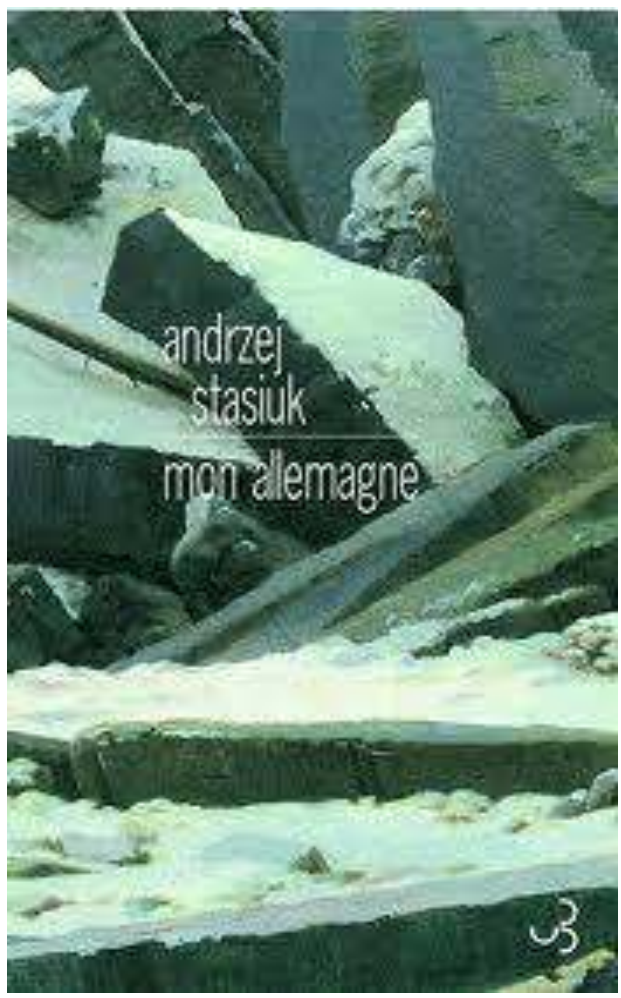
derrière son dévoilement. Parmi ceux-ci, il y a Berlin et son entreprise de produits érotiques « Beate Uhse » ainsi qu'un hôtel à la chambre 609 aux cinq shampoings différents, la ville de Boltenhagen et le chauffeur au tablier bleu rouge de sang ou encore la «Gara de Nord» de Bucarest dans la gare de Stuttgart, espaces dissouts dans l'épiphanie du souvenir. Il y a aussi les réflexions d'un auteur polonais, portant sur le germanisme, la RDA, l'Occident, la Russie, les teutons ou encore le nazisme. Des réflexions lancées comme des chiens enragés dans la quête d'un sens où le passé a du mal à se débattre avec le présent (on peut y voir un des sens du titre original de l'ouvrage, translittération en polonais du mot "Allemagne » en allemand). Ce sont précisément cet entrelacs de pensées prenant la forme de sauts entre différentes cultures ou époques historiques et l'observation par l'auteur du flux de son souvenir qui confèrent à cette prose son caractère évanescent, l'Allemagne se dissipant entre les lignes en brumes abstraites. Stasiuk le souligne d'ailleurs dans son livre lorsqu'il écrit "j'aime que la géographie se transforme en abstraction pure " (p. 34). Tout cela, entre des bouteilles de Jim Beam ou de Johnnie Walker, lorsque le Jim Beam fait défaut.

C'est donc un excellent ouvrage que je recommande aux amoureux de la littérature de lire, de dévorer. Car voici un ouvrage que l'on dévore. Je le recommande aussi aux amoureux de la Pologne car il met en lumière le passé noueux et amer qu'entretient et a entretenu ce pays avec d'une part l'Occident et, plus particulièrement, avec l'Allemagne (mais aussi, à travers le concept de domination, avec la Russie).Stasiuk nous offre ici un livre dont la qualité nous laisse sur notre faim : après en avoir parcouru la dernière ligne, on voudrait continuer, oublier le monde et se plonger dans cet univers échafaudé par le rythme d'une prose limpide. Un beau livre, tout simplement. 
INDEX

Index géographique: Pologne

Index chronologique : XXe siècle

Mots-clés : littérature polonaise

\section{AUTEURS}

MACIEK VANHONNAEKER

Diplômé de l'Université Libre de Bruxelles en slavistique et en philosophie 